\title{
Some Hittite and Armenian Reduplications and Their (P)IE Ramifications*
}

\author{
Paul S. Cohen \\ Yorktown Heights, NY, USA \\ pausyl@aol.com
}

\begin{abstract}
In this paper I summarize the literature on, and generate and defend formally and semantically, explicit derivations for, the Hittite reduplicated pairings \{ "Grš $h a h(h a) r(a)$ 'rake', "hahharie- 'to rake'" $\}$ and \{ "GIšsesarul- 'sieve', "sesarie- 'to sift" $\}$ and the reduplicated Armenian nouns mamul 'press; vice', mamur, 'moss', and mamur 'sawdust', all adduced by Joseph (1992). In addition, I give an explicit derivation for the Hittite reduplicated noun mèmal 'grits, meal'. The first Hittite pairing, the three Armenian nouns, and hitt. Mémal are shown to represent regular instantiations of the nounreduplication process formulated in Cohen (forthc. a); the second Hittite pairing, perhaps surprisingly, turns out to be based on a (P)IE verb-reduplication process. In the course of the exposition, a previously-unreported Armenian sound-change affecting inherited word-final syllabic liquids emerges, and a well-known, but controversial, Armenian sound-change of * $e$ to $a$ is buttressed via a phonological explanation, which has a strong parallel in Old English, eliminating the only putative counterexample. Ultimately, the derivations lead to an elucidation of the semantic functions (thematic roles) of (P)IE reduplicated nouns, with the support of an analogous morphological process in Swahili.
\end{abstract}

\section{Keywords}

noun reduplication - resultatives - instruments - thematic roles - Armenian soundchanges

* I am grateful to Joseph Eska, coeditor of this journal, for his support and for his selection of two perspicacious reviewers, whose comments and queries led to major improvements in this article. Any remaining errors and infelicities are, of course, my responsibility alone.

(C) PAUL S. COHEN, 2014 | DOI: 10.1163/22125892-00201003

This is an open access article distributed under the terms of the Creative Commons 


\section{Introduction}

Joseph (1992:105) has adduced the Hittite reduplicated pairings \{ "GIšhah(ha)$r(a)$ - 'rake'", "hahharie- 'to rake'” $\}$ and \{ "Gršsesarul- 'sieve'”, "sesarie- 'to sift'” $\}$ and the Hittite reduplicated noun memal 'grits, meal' as part of his insightful analysis of the reduplicated Armenian nouns mamul 'press; vice', mamur, 'moss', and mamur 'sawdust'. Making use of one of the accepted (P)IE verb-reduplication processes summarized in $L I V(14-25)$ and the noun-reduplication process delineated in Cohen (forthc. a:§ 9), I generate and defend explicit derivations (in some cases, differing substantially from Joseph's analyses) for the Hittite pairings, a probable Latin cognate of Gršhah(ha)r(a)-, Hitt. mèmal, and the Armenian nouns. I follow these with a discussion leading to an expansion of the semantics of the (P)IE noun-reduplication process.

Hitt. GIšhahhar- 'rake' and hah(ha)riie/a-zi 'to rake'

EDHIL has no entry for these items. However, within EDHIL's analysis of the Hittite verbal system, hah (ha)riie/a-zi 'to rake' is listed (pp.129f.) as a member of the subclass "denominative -ie/a-inflecting verbs" of the class of " $m i$-verbs with a thematic suffix" (there is no mention of the noun anywhere in EDHIL). Both verb and noun can, however, be found in EIEC (581 s.v. thresh), where they are given as reflexes of PIE “* $h_{2} e h_{2} e r$ - 'thresh, rake (for threshing)', along with Lat. "ārea $\left(<* h_{2} e h_{2}\right.$ eriieh $\left._{a}\right)$ 'threshing floor', which is listed as another reflex. EIEC (loc. cit.) references Puhvel (1976), and it turns out that Puhvel's article is the direct source for the subentry in EIEC. Puhvel's argumentation (p. 201) for the cognacy of the Latin noun and both Hittite items ${ }^{1}$ is persuasive, though he wrongly gives the PIE etymon with first, rather than second, laryngeals. Melchert (1994:157) gently corrects this error, writing "Puhvel's comparison ... of hahhara- 'rake' with Lat. àrea 'threshing floor' is attractive, but the shape suggests a reduplicated form * $h_{2} e-h_{2} r-o-. " 2$

It seems an obvious idea that the Hittite stem is indeed, as Joseph and Melchert posit, a reduplication, since it cannot be based directly on a simplex root, given the fact that it would then contravene the PIE root-structure constraint that bars $c_{i} V c_{i} \ldots$ (see, e.g., oHcGL [44], Cooper [2009:56]). I agree with Tischler (1983:122, 169f.) and Joseph (loc. cit., referencing Tischler) that the sim-

1 Puhvel (loc. cit.) specifies that the verb is derived from the noun.

2 Melchert does not mention the verb. 
plex root is the one given in $L I V\left(272 \mathrm{f}\right.$.) as ${ }^{*} h_{2} e r h_{3}$ - 'aufbrechen, pflügen' (about the semantics of which more below).

The basic reduplication process would have been the one delineated for nouns in Cohen (forthc. a:§9), emended slightly here:

1. Copy the initial portion of the $e$-grade root up through the vowel and any immediately-following laryngeal (with [later] consequent coloration and lengthening), and prepose it to the root.

2. a) For intensive reduplications, ${ }^{3}$ reduce the vowel of the preposed portion to zero-grade (with concomitant syllabification of a following sonorant).

b) For resultative reduplications, shift the accent to the preposed portion and reduce the vowel of the (original) root to zero-grade (with concomitant syllabification of a following sonorant).

The derivation of the Hittite forms is as follows:

- $\mathrm{PIE}^{*} h_{2} \mathrm{erh}_{3^{-} \rightarrow}$

- (Step 1 of the noun-redup. process given immed. above) ${ }^{*} h_{2} e h_{2} e r h_{3^{-}}>$

- (Step $2 \mathrm{~b}$ of the noun-redup. process given immed. above) ${ }^{*} h_{2} e h_{2} r h_{3^{-}}>$

- (Laryngeal coloration) ${ }^{*} h_{2} a h_{2} r h_{3^{-}}>$

- (Syllabification of sonorant betw. consonants) ${ }^{*} h_{2} a h_{2 r} r h_{3^{-}}>$

- (Loss of laryngeal in non-initial sylls. of compounds and redups., discussed immed. below) ${ }^{*} h_{2} a h_{2 \sigma} r->$

- (PAnat. reflex of $\left.{ }^{*} h_{2}\right){ }^{*} \hbar a \hbar r-{ }^{-4}>$

3 The intensive noun reduplications referred to here are exemplified and explicated in Cohen (forthc. a). These include Lat. papāver 'poppy' (based formally on *péh $h_{2} \underset{r}{r}$ 'fire' and having a figurative semantic reference to the field poppy's fire-red color), Gk. $\pi \dot{\alpha} \pi \tilde{u} \rho \circ \varsigma^{\prime}$ 'papyrus' (also based formally on *pé $h_{2}$ ur 'fire', but having a literal semantic reference to papyrus's burning with an especially intense flame), and PIE ${ }^{*} b^{h} a-b^{h} e h_{2}$ - 'bean' (based formally on * $b^{h} u e h_{2}$ - 'to grow' and having a semantic reference to the bean-plant's prolific growth pattern). They are to be distinguished as a class, semantically and formally, from those of a different type that are often labeled intensive-which are onomatopoetic and/or emotive, and generated from a $(c) v c$... root by preposing a copy of that root up through the postvocalic consonant. Typical examples are "ocs gla-gol-u 'word' (< "gal-gal-o-, from *gal- 'to cry out')" (Fortson [2010:130]); Lat. “mur-mur 'rumble'[,] ... quer-querus 'causing a person to shiver'[,] ... tur-tur 'turtle-dove'[,] ... up-upa 'hoopoe; pickaxe' ...” (онсGL [267]); “... Grk. ßápßapos 'non-Greek speaker', OInd. barbara- 'stammerer, non-Indic speaker' ..." (EIEC [542 s.v. stammer]).

4 The exact points of articulation of PIE ${ }^{*} h_{2}$ and of its Anatolian reflex are unknown (and, probably, unknowable), but there is good evidence that PIE ${ }^{*} h_{2}$ was a non-glottal post-velar-i.e., 
- (Hitt. reflex of PAnat. syllabic sonorant $)$ hahar- $\left(=\right.$ hahhar $\left.{ }^{5}\right) \rightarrow$

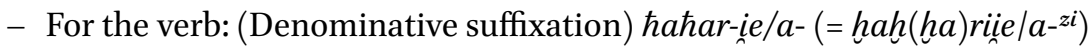

The rule deleting the laryngeal in the stated environment is suggested in $O H C G L$ (113), where we find at the end of a short section on the veorvós Rule:

There may have been a more general rule of laryngeal loss in non-initial syllables of 'long' forms [i.e., compounds and reduplications], to judge from cases like *kom-d ${ }^{h} h_{1} t u$ - 'putting together' > Cōnsus (Roman god of grain storage).

For another example, see the derivation as a noun reduplication of PIE *mēms'meat, flesh' (< ${ }^{*} m e ́ h_{1}-m h_{1} s-$ ) in Cohen (forthc. b). And Michael Weiss (pers. comm.) has also pointed me toward two other relevant references on this topic:

- Lat. vicissim 'in turn; on the other hand' is often etymologized as < *viki$\mathrm{dh}_{3} \mathrm{tim}$ (see EDLOIC [674f., s.v. vicis 'turn, occasion'] for a brief discussion).

- Kuiper (1961), in keeping with the title of his article, focuses on examples from Sanskrit, with occasional excursions into other Indo-Iranian languages. He advocates the position that, for Sanskrit, compositional shortening (i.e., the sort of laryngeal loss we are talking about here) is an Indic or, perhaps, Indo-Iranian phenomenon (see esp. p. 23). However, he does allow for the possibility that at least some of the compositional shortening in his material goes back to PIE: On p. 21 (with fnn. 17 and 18), after citing an 1881 article by Johannes Schmidt as well as another article by Schmidt and the writings of Brugmann and Kuriłowicz, ${ }^{6}$ Kuiper writes, "Nun läßt sich freilich die Möglichkeit eines ursprachlichen Schwundes von -ə- $\left(-\mathrm{H}^{-}\right)$nicht prinzipiell bestreiten." And on p. 23, "Prinzipiell bliebe damit freilich die Möglichkeit offen, die genannten Beispiele mit J. Schmidt und Brugmann aus einer ursprachlichen Lautentwicklung zu erklären ..."

faucal-voiceless fricative; (for discussion of the phonetics of PIE ${ }^{*} h_{2}$ [and ${ }^{*} h_{3}$ ], see Cohen \& Hyllested [2012:54-57 with refs.]). I have used the IPA symbol for a voiceless pharyngeal fricative here as a cover-symbol to represent any voiceless faucal fricative.

5 The spelling - $h$ h - should not be interpreted as representing a phonemic geminate; rather, for Hittite at least, it represents an ungeminated (fortis and/or voiceless) phoneme (see Melchert [1994:22], Kimball [1999:105], EDHIL [27], Hoffner \& Melchert [2008:39]).

6 Notably, Kuiper includes Lat. vicissim in the discussion here. 
The derivation of the Latin form is as follows:

- PIE ${ }^{*} h_{2} e h_{3^{-}} \rightarrow$

- (Step 1 of the noun-redup. process given above) ${ }^{*} h_{2} e h_{2} e r h_{3^{-}}>$

- (Step $2 \mathrm{~b}$ of the noun-redup. process given above) ${ }^{*} h_{2} e h_{2} r h_{3^{-}}>$

- (Laryngeal coloration) ${ }^{*} h_{2} a h_{2} r h_{3^{-}}>$

- (Syllabification of sonorant betw. consonants) ${ }^{*} h_{2} a h_{2 r} r h_{3^{-}}>$

- (Loss of laryngeal in non-initial sylls. of compounds and redups. ${ }^{*} h_{2} a h_{2} r_{-} \rightarrow$

- ("Material-suffix"-derivation, ${ }^{7}$ with concomitant resyllabification) ${ }^{*} h_{2} a h_{2} r$ eio- $\rightarrow$

- (PIE or PItal. abstract/feminine nominalization [of Transponat]) ${ }^{*} h_{2} a h_{2} r$ eiah $2^{->}$

- (PItal. loss of laryngeals, with compensatory lengthening of prec. vowels) *ār-ein̄a $>$

- (PLat. loss of intervocalic $\left.i^{8}\right) * \bar{a} r e \bar{a}->$

- (PLat. shortening of nom. sing. final $\left.\bar{a}^{9}\right)$ àrea

The semantics are based on the chief uses of rakes throughout (pre-)history and to this day. Thus, e.g., the first definition of rake in $O E D 1$ is "An implement ... used in field-work for drawing together hay, grass, or the like, and in gardening for similar purposes, or for breaking up, leveling, and smoothing the surface of the ground ...."

In the Hittite items, we see the second function, "for breaking up ... the surface of the ground" (i.e, "aufbrechen" in $L I V$ 's gloss for * $h_{2} \operatorname{erh}_{3^{-1}}{ }^{10}$ ), which establishes the relationship with plowing. Joseph (1992:105) puts it as follows:

[I]t is likely (so Tischler [1983:122]) that Gišhah $(h a) r(a)$-derives ultimately from the root *AerO-found in Greek ápów 'to plow', Latin aro 'plow', Armenian arawr 'plough', etc., and quite possibly Hitt. harra- 'break, bruise, grind' and/or Hitt. hars- 'rip open, till (soil)', (etc.), with a 'rake' representing an instrument through which a type of working/breaking the ground is accomplished ...

$7 \quad$ My thanks go to Brent Vine and Michael Weiss who, in personal communications, suggested the use of the diachronic processes in this step and the next one of the derivation.

8 See, e.g., OHCGL (83).

9 For discussion, see $O H C G L(232)$.

10 The only example in the entry that does not refer directly to plowing is also the only Anatolian example given; it reads, "?heth. haraszi, härasta 'bricht/brach der Erde auf'". 
$E D H I L$ is a bit equivocal, but, on balance, seems to favor this view. Thus, at the entry for "harra-i / harr- ... 'to grind, to splinter up (wood), to crush (bread) ..." (pp. $300 \mathrm{f}$.), we find a list of cognates such as Gk. áów and Lat. arō, 'to plough' and a diffidently suggested PIE etymon "* $h_{2} \sigma{ } h_{3}-e i,{ }^{*} h_{2} r h_{3}$-énti?"; and in the discussion (loc. cit.), we read:

A connection with PIE * $h_{2}$ erh $_{3}$ - 'to plough' (Gk. ápów and Lat. arō, Lith árti, etc. 'to plough') ... would formally work perfectly indeed. The semantic side of this etymology is debatable, however. If one accepts this etymology, it has to be assumed that PIE ${ }^{*} h_{2} e h_{3^{-}}$originally meant 'to crush', which developed into 'to plough' (from 'to crush the soil', cf. also s.v. hārš ${ }^{i}$ 'to till the soil' $<{ }^{*} h_{2}$ orh $\left._{3}-s^{-}\right)$only after the splitting off of the Anatolian branch.

Along with, e.g., LIV and Joseph, I see nothing particularly strained in this semantic connection or in postulating separate developments in the Anatolian and extra-Anatolian branches.

For Lat. ärea, the first function given in the $O E D 1$ definition is evident: On the threshing floor, rakes were (and still are) commonly used to remove dirt and stones, level sheaves for threshing, form round mounds of grain, smooth piles of grain out (e.g., for measurement), and move large amounts of grain around.

Some formal aspects of the Hittite items need further discussion.

- Puhvel (1976:201) states that it is attested both as a neuter (with nom.acc. sg. Gršhahhar) and as an animate (with nom. sg. hahharaš and acc. sg. Gršhahharan). However, an anonymous reviewer points out that "there is in fact no evidence that the word is neuter in Hittite." Puhvel was apparently misled by "Akkadographic" spellings (occurring in lists) with the bare stem (see Hoffner \& Melchert [2008:242]). The reviewer goes on to say that the word is a secondary animate $r$-stem of the type discussed by Hoffner \& Melchert (2008:116), in which, moreover, the forms ending in -araš and -aran are later replacements; and states, "The word was originally an animate stem ${ }^{*} h_{2} e-h_{2} r\left(h_{3}\right)$-o- (or possibly * $\left.h_{2} e-h_{2} r\left(h_{3}\right)-e h_{2^{-}}\right)$."

- It is noteworthy that hahhar $(a)$ and hah (ha)riie/a have single $r$, while harrahas $r r$. This is straightforwardly handled by the following rule: PIE *VRHV > PAnat. *VRRV (see Melchert [1994:79], where harra- is one of the examples explicitly discussed). The second $a$ in harašzi, hărašta is graphic; the forms actually have the sequence /rš/. This goes back to ${ }^{*} r h_{3} \check{s}$, in which 
the laryngeal is regularly lost (see Melchert [1994:73], where harš- is explicitly discussed).

- Finally, Puhvel (1976:201) writes that the neuter noun is "once misspelled harhar (KBO XI 12 I 6)", and I think this is likely to be the right interpretation of that attestation. It is, however, conceivable that the form is the product of a (presumably folk-etymological) intensive reduplication of the type discussed in the latter portion of fn. 3 above.

\section{Hitt. Grššešarul- 'sieve' and šešariie/a-ai 'to sift/sieve'}

Joseph (1992:105) analyzes Hitt. "Gršsesarul- 'sieve"” as a reduplicated instrument noun, “... with a derived denominal verb sesarie- 'to sift' ..." He continues,

[O]ne might conjecture that Gišsesarul derives from PIE *srew- 'flow' (as in Sanskrit srav-ati, the root being an enlarged form of *ser- 'flow', as in Sanskrit si-sar-ti), with a 'sieve' representing the instrument through which a certain type of flowing, e.g. of grain, is accomplished ...

And $C H D(2013: \check{S}, 449$ f.) has an entry for the verb it straightforwardly gives as šešariške- 'to filter, strain' and another for the noun šešarul 'filter, strainer';11 although the entries reference each other, there is no indication of which might be primary. In contrast, EDHIL suggests an etymology for the Hittite items that is not reduplicative, and, inexplicably, offers contradictory conclusions concerning the relative primacy of the verb and noun. Thus, we find (pp. $129 \mathrm{f}$.), within an analysis of the Hittite verbal system, šešariiie/a ${ }^{z i}$ 'to sieve' placed in the same subclass as hah(ha)riie/a-zi, viz., "denominative -ie/a-inflecting verbs". However, the entry for šešariiie/a-zi (pp. $748 \mathrm{f}$.) gives the verb as primary, with Grššešarul- 'sieve' as a derivative. Later in the entry we see, "The stem to both šešariie/a- and šešarul- must be šešar-." And still later, a suggestion of a connection to ocs sěti, Lith. sijóti 'to sieve' is given, on the basis of which a PIE etymon "* $s e h_{1}$-sr-ie/o-?" is, once again diffidently, offered.

Clearly, both šešariiie/a-zi and Giššešarul- have shapes indicative of reduplication. But other scenarios than those just summarized also need to be examined.

11 The only unbroken attestation for either the verb or the noun (KUB 13.3 ii 4) shows a use that makes the $C H D$ glosses more likely to be accurate. 
For example, based on the fact that the noun shows a $u$ that is not present in the verb, one might argue for two different PIE verb roots being involved as simplexes: PIE (unextended) *ser- 'to stream, vel sim.' for the verb and (extended) *sreu- 'to flow, vel sim.' for the noun. And it would be reasonable to assume that the noun is primary-as I do with the Hitt. rake-words, where the extraAnatolian cognate is a noun with no corresponding verb. The problem with such a solution for šešariiie/a-zi and Grššešarul- lies with supplying a derivation for the verb. If, on the one hand, we assume it goes back to PIE, we have to account for its not matching any of the PIE reduplicated thematic-verb types, as given by $L I V$, in terms of accent and location of full- vs. zero-grade vowels. If, on the other hand, we assume it was generated in Hittite or Proto-Anatolian, we have to deal with the inconvenient fact that Hittite verbs in $i i e / a$ - with attested matching nouns fit the synchronic description of having iie/a- attached to the full noun stem; that is to say, we should expect to find the nonexistent verb $\dagger$ †̌ešaruliie/a-. A possible solution emerges if we take *ser- as the simplex root underlying both verb and noun, and for reduplication to have occurred postPIE. And it is the verb that is primary, as is explicitly demonstrated by Hoffner \& Melchert (2008:59):

The suffix -ul-forms neuter nouns from verbs ...: takšul 'peace, friendship' $<$ takšs- 'to join'. The $a$ of the verb stem is deleted before this suffix: waštul 'sin, offense' < wašta- 'to miss the mark, sin', išhiul 'obligation, treaty' < išhiya- 'to bind', immiul 'mixture' < immiya- 'to mix', paršiul 'crumb' < paršiya- 'to crumble', šešarul 'sieve' < šešariya- 'to sift' ... There is one example from an adjective: aššul 'goodness, favor, well being' < aššu'good', and two from nouns: kazzarnul (a textile) < karza(n)- (weaver's tool) ... and pahharul (an implement ${ }^{12}$ ).

Another verb-based example can be added to these, as given by CHD (1997:P, 108 and 96 resp.): ${ }^{\text {iš }} p \bar{a} p u l(a / i)$-, defined as "(a wooden implement for carrying or arranging loaves of freshly baked bread; a bread tray?)" $\leftarrow$ pap $(a$ ?)-, a verb defined as "(an action performed on fermented dough and resulting in loaves ready for baking; perhaps 'to subdivide or shape')". It is also worth noting that all the nouns produced by the process of -ul-suffixation are instruments or resultatives.

\footnotetext{
12 It seems highly likely that this implement-name is derived from pahhur 'fire', and indeed Gı̌s pahhurula- is defined by $C H D(1997: P, 17)$ as "(an instrument for tending or banking a fire)".
} 
As pointed out above, the process that generates the verb must be post-PIE. Given the existence of CLuv. paršul- 'crumb, morsel' (see EDHIL [643]), that process appears to be Anatolian.

The verb-stem šešar-is generated via a well-attested PIE process, continued into Anatolian: athematic $e$-reduplication of presents (LIV's type 1 g [p. 16]):

- PAnat. *ser- $\rightarrow$

- (Athematic e-redup. of presents) *sésr-/*sésor- >

- If *sésr-:

- (Syllabification of sonorant betw. cons. and morpheme boundary) * sésr- >

- (Hitt. outcome of PAnat. syllabic sonorant) * sésar- (= *̌̌ešar-) $\rightarrow$

- If *sésor-:

- (Hitt. outcome of PAnat. unaccented $o)$ *sésar- $(=$ * šešar- $) \rightarrow$

- For the verb: (Hitt. -ie/a thematization) šešariie/a-zi

- For the noun: (Hitt. -ul-suffixation) šešarul

4

Hitt. mēmal 'grits, meal'; Arm. mamul 'press; vice', mamur 'sawdust', and mamu $\bar{r}^{13}$ 'moss'

The standard etymology for Hitt. mèmal 'grits, meal' comprises a reduplication of an $o$-grade form of *melh ${ }_{2}$ 'to crush, to grind' (see, e.g., Melchert [1994:51], EDHIL [575], Oettinger 2012 [244f.]). But we can appeal to Ockham's razor to eliminate any need for a putative $o$-grade-based noun-reduplication type in PIE or Anatolian, because, as given in Cohen (forthc. a:§ 9), the noun-reduplication process summarized in $\S 2$ above (i.e., reduplication based on the $e$-grade of the root) handles the derivation of mémal. ${ }^{14}$ I give an expanded, more explicit version of the derivation of mèmal here, as well as an explication of the variation between $l$ and $l l$ in attested forms; both the derivation and, more extensively, the explication have benefited from suggestions made by the anonymous reviewer mentioned above.

\footnotetext{
13 Nowadays, $\bar{r}$ (rather than $\dot{r}$ ) is the symbol typically used to represent this Armenian rhotic.

14 Hitt. hāhhal 'greenery, (wild) vegetation, etc.' is sometimes adduced (e.g., by Oettinger [2012:245]) as a parallel for mèmal as an $o$-grade-based reduplication. The problem with that is, as pointed out by Melchert (1994:51), there is no etymology for the simplex root of hăhhal. EDHIL (268 s.v. (Giš) hăhhhal) agrees: "Although the word seems genuinely Hittite ... [it has] no good IE etymology". In any case, as delineated in Cohen (forthc. a:§ 7), it too, like mèmal, can be derived directly from an $e$-grade simplex.
} 
$-\mathrm{PIE}{ }^{*} \mathrm{melh}_{2^{-}} \rightarrow$

- (Step 1 of the noun-redup. process given in $\S 2){ }^{*} m e-m e l h_{2}->$

- (Step $2 \mathrm{~b}$ of the noun-redup. process given in $\S 2$ ) *mémlh ${ }_{2}->$

- (Syllabification of sonorant between consonants) * $m e ́ m l h_{2}->$

- (Hittite development for nom.-acc. sing.) * mém! 15

- (Normal Hittite development of PAnat. syllabic sonorants) *mémal- >

- (Hitt. lengthening of short vowels in accented open syllables) mémal-

There is a great deal of attested variation throughout the paradigm of this word between forms with single $l$ and those with $l l{ }^{16}$ This can be attributed to the influence of the verb mall/ $i$-, malliya/ $i$ - 'to mill, grind'; the relationship between this verb and the reduplicated noun would have been transparent to Anatolian/Hittite speakers. In this regard, it is worth noting that forms based on the unextended root, simplex or reduplicated, seem to have come to refer primarily to the grinding of grain, whereas, as illustrated by cLuv. (simplex and reduplicated) malwa-, mammalwa-/mammalhu-, those based on the $u$-extended root refer to crushing or breaking.

Let us turn now to the Armenian items. Joseph (1992:101), giving Djahukian (1990:2) as his source for these, begins his article as follows:

There are several reduplicated nouns in Armenian ... that share a common phonetic shape of mamuR-, where-R-stands for any liquid ...: mamul 'press, vice' (Classical) ... [,] mamur 'moss' (Classical) ... [and] mamur 'sawdust' (modern dialectal).

Joseph does not offer any specifics about a reduplication process for generating these forms; however, citing Djahukian, he gives for their underlying simplex roots (p. 102), respectively, *mel(H)- 'crumble, grind', * $m(e) u-s^{-}$, and *mer $(H)$ 'rub; wear (out); strike'. Updated, these would be, respectively, *melh $2^{-}$, *meus-

15 Hittite noun stems in - - l are neuter and endingless in the nominative and accusative singular; forms in the other cases have vowel-initial endings (see Hoffner \& Melchert [2008:106]). Laryngeals in absolute-final position are lost (see Melchert [1994:87, 180], Kimball [1999:425]). The other case forms would not have lost the laryngeal, however, since a vowel followed it. (Note that the rule ${ }^{*} V R H V>{ }^{*} V R R V$ was no longer operational by the time ${ }^{*} R>a R$ in Hittite; see, e.g., the discussion in Kimball [1999:411] based on Melchert's analysis). The paradigm was then leveled, as one would expect, to the form without laryngeal.

16 Melchert (1994:51) writes that in the oblique forms they are of approximately equal frequency. 
'moss, mold; damp' (see EIEC [385, s.v. moss], Watkins [2000:56]), and * merh ${ }_{2}$ (see $L I V$ [440]). I offer explicit reduplication derivations here.

For both mamul and mamur:

- PIE ${ }^{*} m e R h_{2^{-}} \rightarrow$

- (Step 1 of the noun-redup. process given in $\S 2){ }^{*} m e-m e R h_{2}$ - >

- (Step 2 b of the noun-redup. process given in $\S 2$ ) ${ }^{*} m e m R h_{2}->$

- (Syllabification of sonorant between consonants) ${ }^{*} m e m R h_{2} h^{->}$

- (Loss of laryngeal in non-initial sylls. of compounds and redups.) * $m e m R$ - >

- (Proposed rule for Parm., discussed below) *memuR- >

- (PArm. lowering of $e$ by $u$ in foll. syll., discussed below) mamuR

The reflex of PIE syllabic liquids and nasals in Armenian is generally accepted as $a+$ liquid/nasal, as evidenced by such works as EIEC (28), Beekes apud Kortlandt (2003:151), and Fortson (2010:386), with Fortson adding the explicit proviso: "Word-finally, the syllabic nasals became $-n$, as in the numerals ewt'n 'seven' and tasn 'ten' from *septm and *dekm."17 I am hereby proposing, in addition, a specific assimilative development word-finally (or, alternatively, in closed syllables) for syllabic liquids and nasals after $m$-namely $u+$ liquid/nasal. ${ }^{18}$ This would yield the final sequences of mamul and mamur. As derived below, the $u$ of mamur continues the $u$ from the underlying simplex root.

Armenian lowering of $e$ by $u$ in a following syllable has long been accepted by many scholars; for a modern example, see Clackson (1994:126f.), who adduces

17 Presumably, in the case of word-final * $m$, this occurred in stages-perhaps, * $m>{ }^{*} a m>$ *an $>n$.

18 As pointed out by an anonymous reviewer, my proposal is quite similar to one made by Olsen (1999:806) in the section entitled "Notes on the phonological development from IE into Armenian": "All labio-velars as well as * $p$ and * $u$ appear to have a rounding effect on a following vocalic liquid ${ }^{*} r$ or ${ }^{*}$ l, sometimes resulting in $(u) R$, in other cases $o R$." Olsen goes on (pp. 8o6f.) to give four examples of the former type and three examples of the latter type; I note, however, that that same reviewer finds all these examples "shaky". Olsen (1999:779) also gives, without explicit discussion of rounding effects, the following: " ${ }^{-}-h_{1} h_{1}$ $>-a l(v)-:$ malem 'I grind' < * mull $h_{1} e^{-"}$. Moreover, in an analysis of the derivation of $\bar{r} r(=a w r)$ 'day', she writes (p. 177): “... [I]t may ... be possible that $\bar{o} r$ is actually identical with $\hat{\eta} \mu \alpha \rho$ if it is accepted that a vocalic ${ }^{*} r$ is continued as $u r$, not $a r$, in connection with a neighbouring

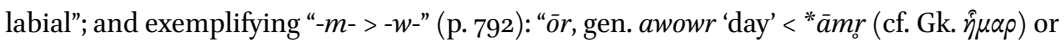
*āmōr". I will return to this word later in the present section. 
vat'sun 'sixty', beside vec ' 'six'. This sound-change has been rejected by some scholars, however - in particular, members of the "Leiden school". Thus, citing Kortlandt (1994), ${ }^{19}$ Beekes apud Kortlandt (2003:156) writes:

${ }^{*} e>a \ldots$ is only found in the following words.

*dekm: tasn 'ten'-Gr. déxa, Lat. decem, Skt. dáśa

*sueks-: vat'sun 'sixty'; cf. vec "six' < * sueks

Kortlandt considers the $a$ the reduced grade (from cases where it appeared regularly as shwa secundum) that replaced zero grade vocalism

And we find in EDAIL (590 f. s.v. vat'sun):

The explanation of the change $\mathrm{e}>\mathrm{a}$ through the lowering influence of the $\mathrm{u}$ in the following syllable ... is disproved by PIE *peruti $>$ Arm. heru 'last year' ... Most probably the vowel -a- can be explained by assuming a zero-grade form taken from the ordinal ...

Leaving aside the a priori unlikelihood of ordinal numbers causing changes in their cardinal counterparts (rather than the other way around), I propose a phonological solution for this problem. Beekes apud Kortlandt (2003:154) tells us:

Armenian shows no trace of the Indo-European accent. In the oldest phase we can reconstruct, the penultimate syllable ... was stressed. At a certain stage, as a result of this stress the following = last syllable was lost; not only the vowel, but the consonants following the vowel disappeared as well, except $r, l, n$ (note that at this time ${ }^{*}-m$ had become $-n$ ) ...

Before final-syllable loss, the $/ \mathrm{u} /$ of * peruti would have been stressed and the /e/ unstressed, whereas the $/ \mathrm{u} /$ of ${ }^{*} m e m u R$ would have been unstressed and the /e/ stressed. Though this difference might, at first blush, seem insignificant, the Armenian lowering (or, equally, retraction) by / $\mathrm{u} /$ in a following syllable of /e/—only when stressed - to /a/ is remarkably similar in every aspect to the prehistoric Old English sound change in which /æ/—only when stressed—in open syllables became /a/ when there was a back vowel in the following syllable

19 The relevant portions can be found reprinted in Kortlandt (2003:100). 
(see, e.g., Hogg [2011:93ff.]). The anonymous reviewer cited in fn. 18 above writes, "Since ... mamowl [= mamul] is an o-stem, ${ }^{20}$ the pre-form is *mamuloand the accent must have been on the vowel $/ \mathrm{u} /$ in most of the paradigmatic forms, just as in *perúti." One solution to this potential problem is to assume that mamul (as well as mamur) was originally treated as a root noun, which became an $o$-stem secondarily. The reviewer notes that "root nouns are usually continued as i-stems in Classical Armenian". However, there are examples of root nouns that have become $o$-stems; Olsen (1999:816) mentions "att with the specialized meanings 'filth' and 'afterbirth" and "erbowc 'breast' < * $b^{\text {h }}$ rugs (or *b $b^{h} r u \hat{g} s$ ) and perhaps sowr 'sword' if < *koh ${ }_{3} s$.

The derivation of mamur is as follows:

- PIE *meus- $\rightarrow$

- (Step 1 of the noun-redup. process given in §2) *me-méus- >

- (Step 2a of the noun-redup. process given in §2) *mméus- $\rightarrow$

- (Primary nominal suffixation with concomitant vowel reduction) *mmusró- >

- (PArm. normal outcome of syll. nasal after $m$, word-internally [or in open syllable]) *mamusró- >

- $\left(\right.$ PArm. $\left.{ }^{*} s r>\bar{r}^{21}\right)$ *mamuróó- $>$

- (PArm. stress shift to penult) *mamúro- >

- (Arm. apocope $\left.{ }^{22}\right)$ mamur

The same anonymous reviewer has brought up the need to explicate another formal point that arises in the derivation of $\bar{o} r(=a w r)$ 'day': viz.,

... the question of how old a group /amu/ in Armenian can be in view of awr 'day' < *amur < *āmōr which is usually understood to have developed with $\mathrm{u}$-epenthesis via *aumur $>{ }^{*} \mathrm{a} \mathrm{u}^{\mathrm{u}} \mathrm{ur}>\mathrm{awr}$. Would one not expect the same development in the case of reduplicated nouns with the sequence /amu/, i.e. * mamuR > *mau ${ }^{\mathrm{u}} u r>\dagger$ mawR?

20 I note that EDAIL (446) also lists mamul as an $o$-stem-though citing a 19th century dictionary that gives inflected forms "without evidence".

21 See, e.g., Beekes apud Kortlandt (2003:197).

22 As, e.g., specified in the quote from Beekes apud Kortlandt (2003:154) given earlier in this section, and op. cit. (210f.). 
The question is, of course, eminently reasonable; however, the answer is crucially dependent on whether *amur and *mamuR have parallel histories. To make this determination, we need to look closely at the phenomenon of Armenian $u$-epenthesis. Olsen (1999:798-801) discusses $u$-epenthesis in detail, listing a dozen examples (including $\bar{o} r$ ). She concludes her discussion as follows:

[I]t may be quite tentatively suggested that the IE accent was still working when the process of $u$-epenthesis commenced: an unstressed $-u$ - of a final syllable was anticipated in the preceding stressed syllable, while an originally stressed $-u$ - in the same position was left unaltered until the fixing of stress on the old penult and eventual apocope of final syllables ... $U$-epenthesis would thus be dated quite early ... It will be observed that we have no certain evidence for $u$-epenthesis triggered by ${ }^{*} \bar{o}$ since the paradigm of $\bar{o}$, awowr may be interpreted on the basis of lenition of *- $m$ by an adjacent ${ }^{*}-\bar{o}$ -

Olsen's suggestion would yield a straightforward explanation of the outcome of $/ \mathrm{amu} /$ in awrvs. that in mamul and mamur:It merely requires that $u$-epenthesis preceded the development of ${ }^{*} R$ to $V R$, and that, pace Olsen's statement ending the discussion, $a w r$ is indeed based on * $\bar{a} m \bar{o} r$, not ${ }^{*} \bar{a} m r$. Obviously, because of its stress pattern, at no stage of its development did mamur fit the structural requirements for $u$-epenthesis.

One more query from the same reviewer:

Since ... reduplication is a productive means of word formation in Armenian, it seems less problematic to assume that these nouns are innerArmenian creations (for mamowr cf. mowr 'soot; ink', for mamowr cf. mowr' 'wet mortar, cement') ...

Clearly, derivational dependencies of this sort cannot be semantically direct, since, of course, sawdust and moss were familiar to IE speakers much earlier in (pre-)history than were ink and mortar. The reviewer does, however, point out in a subsequent note the possibility that "the innovated (i.e. reduplicated) forms may have retained the older meanings ..., while the old forms shifted semantically to newer meanings ..." But the formal facts argue strongly against such a solution, and so for a PIE-based derivation instead: Although it is true that reduplication is a productive means of word formation in Armenian, the type having the form civcivc[...] is unusual in the language. Thus, e.g., Olsen 
(1999:758) lists 35 representative examples of Armenian adjectival, adverbial, and substantival reduplicated formations; of these, not a single one is formally $\operatorname{civcivc}[\ldots] . .^{23}$

I have, in the present article, given explicit etymologies as reduplications for Hitt. Gišhah (ha)r(a)- 'rake', hahḩarie- 'to rake', Grššešarul- 'sieve', šešarie- 'to sift', mèmal 'grits, meal'; Lat. àrea 'threshing floor'; and Arm. mamul 'press; vice', mamur 'sawdust', mamur 'moss'. Of these, while mamur is a further example of what are referred to in Cohen (forthc. a) as intensive noun reduplications, Gišhah $(h a) r(a)-$, mèmal, àrea, mamul, and mamur are examples of what is termed resultative noun reduplications there. Semantically, however, Grš hah $(h a) r(a)$ - and mamul are clearly instruments, not resultatives. It would appear, then, that this sort of noun reduplication can generate items in both semantic classes. We can add another member to the class of instruments generated in this fashion: Hitt. Giš uauarkima-, ${ }^{24}$ traditionally glossed as 'door-hinge' but, as argued in EDHIL (991 s.v.), probably better taken as meaning "that part of the threshold or doorpost in which the door-axle is fixed and turns[;] ... perhaps ... some kind of wooden bearing between the wooden axle and the stone threshold". In addition, PIE * $k^{u} e-k^{u} l h_{1}-o$ - 'wheel'-which, following Manaster Ramer (2010:2), is derived as a morphological and semantic resultative in Cohen (forthc. a:§ 8) -falls, of course, comfortably in the semantic class of instruments as well. The production of both resultatives and instruments via a single morphological process, though perhaps seeming unmotivated, has a strong parallel in the Swahili process of nominalizing verbs by appending an -o suffix to the verb stem (as opposed to other Swahili nominalizing processes, which have different semantic functions with respect to thematic-role interpretation). The following observations are from Benji Wald (pers. comm.), who supplied abundant data; I have selected these examples as representative: ${ }^{25}$

23 The reviewer is in agreement about the formal facts, writing, "apparently all clearly inner-Armenian reduplicated nouns show full root reduplication ..." However, it is only fair to note that Leroy (1986), focusing on nominal reduplications found in Classical Armenian, gives 136 examples, of which 14 (to be found on pp. 72 f.), including mamur, can be taken as $c_{i} V c_{i} v c[\ldots]$.

24 See Cohen (forthc. a: $\$ 7$ ) for detailed etymological discussion.

25 All five of the examples included here under my heading of Instrument can be found in Ashton (1944 [1982]:287). Under my heading of Resultative, the example of waza $\rightarrow$ waz-o is 
- Instrument

- fagia 'to sweep' $\rightarrow u^{26}$-fagi-o 'broom'

- funga 'to close' $\rightarrow$ ki-fung-o 'button' (i.e., 'fastener')

- fungua 'to open' (lit., 'to unclose') $\rightarrow$ u-fungu-o 'key'

- tega 'to trap' $\rightarrow$ m-teg-o 'trap'

- ziba 'to stop up' $\rightarrow$ ki-zib-o 'stopper' (e.g., 'cork')

- Resultative

- panga 'to arrange, put in order' $\rightarrow$ m-pang-o 'plan, arrangement'

- shindana 'to compete' (lit., 'to strive to win against one another') $\rightarrow$ shindan-o 'contest'

- umba 'to shape, form' $\rightarrow$ umb-o 'shape, form'

- waza 'to think, imagine' $\rightarrow$ waz-o 'idea, thought'

- $z a a$ 'to cause to be born, bring into being' $\rightarrow$ ma-za-o 'product, produce, progeny'

One final note: As highlighted by Joseph (1992:104), the existence of Hitt. mèmal 'grits, meal' and Arm. mamul 'press; vice' (both based on PIE *melh ${ }_{2}$ - zerreiben, mahlen') shows that resultative and instrument noun reduplications generated from the same PIE simplex root can occur in the daughter languages, and presumably even in PIE itself.

\section{References}

Ashton, E.O. (1944 [1982]). Swahili Grammar (Including Intonation). 2nd edn. (repr.). N.p.: Longman.

CHD = Hans G. Güterbock, Harry A. Hoffner \& Theo P.J. van den Hout (eds.) (1979-).

The Hittite Dictionary of the Oriental Institute of the University of Chicago. Chicago: The Oriental Institute of the University of Chicago.

Clackson, James (1994). The Linguistic Relationship of Armenian and Greek. Oxford \& Cambridge (MA): Blackwell.

Cohen, Paul S. (forthc. a). "Reduplicated Nouns in IE". Paper based on presentation given on 20 Sept. 2012 at the 14th Fachtagung of the Indogermanische Gesellschaft in Copenhagen (to appear in the Proceedings of the Gesellschaft).

also in Ashton (op. cit.: 288), whereas the other four examples were furnished by Wald. It should be noted that I have used Resultative in conformity with the terminology employed throughout this paper (following Cohen [forthc. a]); however, for some of the examples in this grouping, Wald understandably prefers Process, and I concur.

26 Prefixes on nouns in these examples are Swahili gender-class markers. 
Cohen, Paul S. (forthc. b). "A new etymology for PIE *mēms- 'meat, flesh'”. Paper based on presentation given on 10 Oct. 2013 at the 2 nd Colloquium on Indo-European in Brno (to appear in Linguistica Brunensia).

Cohen, Paul S. \& Adam Hyllested (2012). "A New Sound Law of PIE: Initial ** $h_{3} u>$ * $h_{2} u$ ". In Benedicte Nielsen Whitehead, Thomas Olander, Birgit Anette Olsen \& Jens Elmegård Rasmussen (eds.) The Sound of Indo-European: Phonetics, Phonemics, and Morphophonemics. Copenhagen: Museum Tusculanum.

Cooper, Adam I. (2009). "Similarity Avoidance in the Proto-Indo-European Roots". University of Pennsylvania Working Papers (= Proceedings of the 32nd Annual Penn Linguistics Colloquium) 15.1:55-64.

Djahukian, Gevork (1990). “Combinatory Vowel Changes in Armenian”. Annual of Armenian Linguistics 11:1-16.

EDAIL $=$ Hrach K. Martirosyan (2010). Etymological Dictionary of the Armenian Inherited Lexicon. Leiden \& Boston: Brill.

$E D H I L=$ Alwin Kloekhorst (2008). Etymological Dictionary of the Hittite Inherited Lexicon. Leiden \& Boston: Brill.

EDLOIC $=$ Michiel de Vaan (2008). Etymological Dictionary of Latin and the Other Italic Languages. Leiden \& Boston: Brill.

EIEC $=$ J.P. Mallory \& D.Q. Adams (eds.) (1997). Encyclopedia of Indo-European Culture. Chicago \& London: Fitzroy Dearborn.

Fortson, Benjamin W., IV (2010). Indo-European Language and Culture: An Introduction. 2nd edn. Malden (MA), Oxford \& Chichester: Wiley-Blackwell.

Hoffner, Harry A., Jr. \& H. Craig Melchert (2008). A Grammar of the Hittite Language. Part 1: Reference Grammar. Winona Lake (IN): Eisenbrauns.

Hogg, Richard M. (2011). A Grammar of Old English. Vol. 1: Phonology. Malden (MA) \& Oxford: Wiley-Blackwell.

Joseph, Brian (1992). "Armenian Reduplicated Nouns mamul, mamur, and mamur". In John A.C. Greppin (ed.) Proceedings of the Fourth International Conference on Armenian Linguistics: Cleveland State University, Cleveland, Ohio, September 14-18, 1991, 101-114. Delmar (NY): Caravan.

Kimball, Sarah E. (1999). Hittite Historical Phonology. Innsbruck: Innsbrucker Beiträge zur Sprachwissenschaft.

Kortlandt, Frederik. (1994). "Proto-Armenian Numerals”. In Jens Elmegård Rasmussen \& Benedicte Nielsen (eds.) In Honorem Holger Pedersen: Kolloquium der Indogermanischen Gesellschaft vom 26. bis 28. März 1993 in Kopenhagen, 253-257. Wiesbaden: Dr. Ludwig Reichert Verlag. [Repr. in Kortlandt (2003:98-101).]

Kortlandt, Frederik (2003). Armeniaca: Comparative Notes (with an Appendix on the Historical Phonology of Classical Armenian by Robert S.P. Beekes). Ann Arbor (MI): Caravan.

Kuiper, F.B.J. (1961). “Zur kompositionellen Kürzung im Sanskrit”. Die Sprache 7:14-31. 
Leroy, Maurice (1986). "Le redoublement comme procédé de formation nominale en arménien classique”. In Maurice Leroy \& Francine Mawet (eds.), La place de l'arménien dans les langues indo-européennes, 62-75. Louvain: Lovanii Aedibus Peeters.

$L I V=$ Helmut Rix (ed.) (2001). Lexikon der indogermanischen Verben. 2nd edn. Wiesbaden: Dr. Ludwig Reichert Verlag.

Manaster Ramer, Alexis. 2010. "A Simply Perfect Bear of an Etymology, or Two, or Even More: PIE * $h_{2} r t-t-\hat{k} o$ - [sic] 'bear', OInd. rkșá 'bald, bare', PIE *te-tk-on- 'craftsman' (with some discussion of * $k^{w} e k^{w-l-o-[s i c] ~ ' w h e e l ', ~ m e ̀ m s ~ ' m e a t ', ~ * t e t r-~ ' g r o u s e ', ~ a n d ~ s e v e r a l ~}$ other "perfect" nouns)". Unpublished (and unfinished) ms. emailed to me by the author in Oct. 2010.

Melchert, H. Craig (1994). Anatolian Historical Phonology. Amsterdam \& Atlanta: Rodopi.

OED1 $=(1933$ [1971]). The Compact Edition of the Oxford English Dictionary. London: Oxford University Press.

Oettinger, Norbert (2012). "Das Verhältnis von nominaler und verbaler Reduplikation im Indogermanischen und Anatolischen". In H. Craig Melchert (ed.), The IndoEuropean Verb:Proceedings of the Conference of the Society for Indo-European Studies, Los Angeles 13-15 September 2010, 241-246. Wiesbaden: Reichert.

OHCGL = Michael Weiss (2009). Outline of the Historical and Comparative Grammar of Latin. Ann Arbor (MI) \& New York: Beech Stave.

Olsen, Birgit Anette (1999). The Noun in Biblical Armenian: Origin and Word-Formation-with Special Emphasis on the Indo-European Heritage. Berlin \& New York: Mouton de Gruyter.

Puhvel, Jaan (1976). "Latin àrea and Indo-European Threshing Terminology in Hittite". California Studies in Classical Antiquity 9:197-202.

Tischler, Johann (1983). Hethitisches etymologisches Glossar. Part 1 (a-k). Innsbruck: Institut für Sprachwissenchaft der Universität Innsbruck.

Watkins, Calvert (2000). The American Heritage Dictionary of Indo-European Roots. 2nd edn. Boston \& New York: Houghton Mifflin. 